\title{
Characterization of Fusarium and Neocosmospora Species Associated With Crown Rot and Stem Canker of Pistachio Rootstocks in California
}

\author{
Maria Crespo, ${ }^{1}$ Daniel P. Lawrence, ${ }^{2}$ Mohamed T. Nouri, ${ }^{1}$ David A. Doll, ${ }^{3}$ and Florent P. Trouillas ${ }^{1, \dagger}$ \\ ${ }^{1}$ Kearney Agricultural Research and Extension Center, Department of Plant Pathology, University of California, Davis, Parlier, \\ CA 93648 \\ ${ }^{2}$ Department of Plant Pathology, University of California, Davis, CA 95616 \\ ${ }^{3}$ University of California Cooperative Extension Merced County, Merced, CA 95341
}

\begin{abstract}
California produces $99.1 \%$ of pistachios grown in the United States, and diseases affecting pistachio rootstocks represent a constant challenge to the industry. Field surveys of fungi associated with pistachio rootstocks with symptoms of crown rot and stem canker in three central California counties followed by phylogenetic analyses of translation elongation factor $1-\alpha$ and second largest subunit of RNA polymerase II gene fragments identified three Fusarium species (Fusarium equiseti, Fusarium oxysporum, and Fusarium proliferatum) and two Neocosmospora species (Neocosmospora falciformis and Neocosmospora solani). F. oxysporum and $N$. falciformis were the fungal species most frequently recovered from symptomatic pistachio trees.

Inoculations of detached twigs of cultivar Kerman pistachio Pioneer Gold I and clonal University of California, Berkeley I (UCBI) rootstocks showed that all five species could colonize pistachio wood and cause vascular discolorations. Pathogenicity tests in potted pistachio trees completed Koch's postulates and confirmed that $F$. oxysporum, $F$. proliferatum, $N$. falciformis, and $N$. solani were capable of producing rot and discoloration in stems of clonal UCBI rootstocks, the most widely planted pistachio rootstock in California. To our knowledge, this study is the first to present insights into the biodiversity and biology of Fusarium and Neocosmospora species associated with pistachio trees in California.
\end{abstract}

Pistachios (Pistacia vera L.) grown in California account for $>99 \%$ of all pistachios produced in the United States, the world's second largest pistachio producer behind Iran (Geisseler and Howarth 2016). As the acreage of pistachio continues to grow in California, fungal diseases present a continuous challenge to the industry, often causing severe economic losses. The most frequently observed aboveground fungal diseases affecting pistachio in California are Botryosphaeria panicle and shoot blight caused by multiple species in the Botryosphaeriaceae (Michailides and Morgan 2004), Alternaria late blight caused by multiple species of Alternaria Nees (Pryor and Michailides 2002), and Botrytis blossom and shoot blight caused by Botrytis cinerea Pers (Michailides 2005). The epidemiology of these diseases of pistachio in California is mainly driven by climatic factors, such as cool, wet springs, as documented by severe Botryosphaeria panicle and shoot blight in the late 1990s, whereby $\sim 32$ million pounds of pistachios were lost (Michailides and Morgan 2004). Aboveground diseases of pistachio rarely lead to the death of entire trees, but rather, they largely effect nut quality and quantity.

Verticillium wilt caused by Verticillium dahliae Kleb and Phytophthora root and crown rot caused by Phytophthora de Bary spp. are among the most important soilborne diseases affecting pistachios. Historically, Verticillium wilt has been the most destructive disease of pistachio in California (Holtz and Teviotdale 2016; Michailides 2005). Verticillium wilt is more prevalent in the southern half of the San Joaquin Valley, and it is typically most destructive to pistachio trees that are grown in fields that were previously planted with other susceptible crops, such as cotton, tomato, and melon (Holtz and Teviotdale 2016). The most common symptom of Verticillium wilt

${ }^{\dagger}$ Corresponding author: F. P. Trouillas; flotrouillas@ucdavis.edu

Funding: We thank the California Pistachio Research Board for financial support.

The author(s) declare no conflict of interest.

Accepted for publication 22 February 2019.

() 2019 The American Phytopathological Society of pistachio is a general lack of plant vigor usually followed by a rapid desiccation and death of one scaffold or the entire tree. Cool spring or mild summer temperatures and moist soil usually favor Verticillium wilt. However, the development of the Verticillium wilt-resistant University of California, Berkeley I (UCBI) rootstock has mitigated this disease in California. UCBI rootstocks (clonal or seeded) have been the most widely utilized rootstocks by the pistachio industry in California; therefore, Verticillium wilt of pistachio has become infrequent in the San Joaquin Valley.

Phytophthora spp. in California pistachios have historically been associated mainly with cankers in the scion, causing girdling of limbs and trunks (MacDonald et al. 1992) and thus, reducing yields. In California, Phytophthora parsiana Mostowf, DEL Cooke \& Banihashemi and Phytopythium helicoides (Drechsler) Abad, de Cock, Bala, Robideau, Lodhi \& Lévesque have been reported to cause crown rot and root rot, respectively, on pistachio rootstocks (Fichtner et al. 2016a, b). Prolonged periods of high soil moisture promote diseases caused by Phytophthora species; therefore, water management is essential for control. Sprinklers should be set to avoid irrigation water from hitting the trunk or cause pooling around the crown of the trees (Holtz and Teviotdale 2016). Occasionally, Armillaria root rot caused by Armillaria mellea (Vahl) P Kumm can occur in pistachio in California (Holtz and Teviotdale 2016). Armillaria root rot is predominately associated with pistachio orchards that were established on lands that were previously natural oak woodlands, whereby deep-rooted infected oak root remnants serve as natural inoculum sources for newly planted pistachio trees. Trees affected by Armillaria root rot show reduced growth, usually on one side of the tree, and early yellowing of leaves followed by defoliation; on the roots, mycelial plaques and rhizomorphs are signs of this disease (Holtz and Teviotdale 2016). The selection of the rootstock is one of the most important decisions a grower can make in association with knowledge of previous cropping systems and documented occurrence of soilborne pathogens on lands intended for pistachio production.

In California, the aforementioned fungal diseases of pistachio have long been known to occur in portions of the Sacramento and San Joaquin Valleys. During 2015 and 2016, surveys were conducted in the main pistachio-growing counties in central California to detect potential new and emerging diseases of pistachio and recognize 
possible new threats to the industry. Diseases reported from these surveys have included new canker diseases causing wood discoloration as well as branch dieback of pistachio (Nouri et al. 2019). Additional issues detected from surveys of pistachio orchards have included unique disease symptoms on UCBI rootstocks. Trees exhibited a general decline with chlorotic foliage associated with crown rot symptoms in the rootstock. Subsequent isolations from rotted tissues revealed numerous Fusarium-like isolates. Similar fungi also were detected from lesions developing near sites of mechanical injuries on the stems of pistachio rootstocks. The common occurrence of Fusarium-like isolates in diseased tissues of pistachio called into question the identity, biology, and ecological function of these fungi. Therefore, our objectives were to (i) identify and characterize the putative pathogens associated with symptomatic pistachio tissues and (ii) evaluate their pathogenicity to detached branches of cultivar Kerman, Pioneer Gold I (PGI), and UCBI and potted UCBI pistachio rootstocks.

\section{Materials and Methods}

Disease symptoms and origin of fungal isolates. Declining pistachio trees with crown rot symptoms in UCBI rootstocks were detected in six young to mature orchards located in Fresno, Kern, and Merced Counties in 2015 and 2016. Five symptomatic trees per orchard were sampled. Samples of necrotic bark and cambium tissues from the crown were collected using a hatchet and taken to the laboratory for additional study. Additional samples were obtained from root lesions, cankers, wood discolorations, and other lesions on the stems of pistachio rootstocks in mature orchards. For isolation of fungi or oomycetes, small pieces $(5 \times 5 \mathrm{~mm})$ from the margin between discolored and healthy phloem and cambium tissues were submerged in $0.5 \%$ sodium hypochlorite for $2 \mathrm{~min}$. Pieces were then rinsed twice in sterile water before being placed onto potato dextrose agar (39 g/liter; Sigma-Aldrich) medium acidified to $\mathrm{pH} 4.5$ to 5.0 with lactic acid (APDA; $2.6 \mathrm{ml}$ of $25 \%$ [vol/vol] lactic acid per liter of medium) and PARP (Pimaricin + ampicillin + rifampicin + pentachloronitrobenzene) medium (Erwin and Ribeiro 1996), and they were incubated at $25^{\circ} \mathrm{C}$ for 4 to 7 days. Emerging hyphae were subcultured to fresh potato dextrose agar (PDA), and pure cultures were obtained by generating single-spore isolates from the developing colonies as described previously (Leslie and Summerell 2006) for phylogenetic and morphological analyses.

DNA extraction, polymerase chain reaction amplification, sequencing, and phylogenetic analyses. Total genomic DNA was isolated from $~ 7$-day-old PDA cultures by gently scraping the mycelium with a sterile scalpel and following the manufacturer's protocol for the FastDNA Spin Kit (MP Biomedicals). All polymerase chain reactions (PCRs) utilized AccuPower PCR Premix (Bioneer). Translation elongation factor 1- $\alpha$ (TEF1) was amplified using the primer pairs EF1/EF2 (O'Donnell et al. 1998), and two portions of the second largest subunit of RNA polymerase II ( $R P B 2)$ were amplified using the two sets of primer pairs 5f2/7cr and $7 \mathrm{cf} / 11$ ar (Liu et al. 1999; Reeb et al. 2004). Amplification products were visually checked on a $1.5 \%$ agarose gel for presence and size via electrophoresis ( $90 \mathrm{~V}$ for $25 \mathrm{~min}$ ) and ultraviolet illumination followed by purification using ExoSap-IT Product Cleanup Reagent (Affymetrix). PCR amplicons were sequenced bidirectionally using an ABI 3730 Capillary Electrophoresis Genetic Analyzer (College of Biological Sciences Sequencing Facility, University of California, Davis).

Forward and reverse DNA chromatograms were assembled, proofread, and edited in Sequencher v. 5 (Gene Codes Corporation), and consensus sequences (Table 1) were subjected to BLASTn queries in NCBI and FUSARIUM-ID (Geiser et al. 2004) to obtain preliminary identifications and sequences with high similarity to representative specimens for phylogenetic reference (Table 1). The multiple sequence alignments were conducted in MEGA v. 6 (Tamura et al. 2013) and manually adjusted where necessary in Mesquite v. 3.10 (Maddison and Maddison 2016). Alignments were submitted to TreeBASE under the accession number S23384. The combined dataset $(T E F 1+R P B 2)$ was analyzed using two different optimality search criteria, maximum parsimony (MP) and maximum likelihood
(ML), in PAUP* v. 4.0b10 and MEGA v. 6 (Swofford 2002; Tamura et al. 2013), respectively. MP analyses consisted of heuristic searches with 1,000 random sequence additions implemented with the TreeBisection-Reconnection algorithm, with gaps treated as missing data. Branch support was estimated by 1,000 bootstrap replicates. For ML analyses, MEGA was used to infer the best model of nucleotide substitution for the dataset using the Akaike information criterion (AIC). The ML analysis used the nearest neighbor interchange heuristic search method, and clade support was estimated by 1,000 bootstrap replicates. Sequences of Cyanonectria buxi (Fuckel) Schroers, Gräfenhan \& Seifert (Hypocreales, Nectriaceae) isolates CBS 125551 and BBA 64985 served as the outgroup taxon in the phylogenetic analyses.

Morphology. Mycelial plugs (5 $\mathrm{mm}$ in diameter) were taken from the margins of selected actively growing cultures (Kearney Agricultural Research and Extension 394 [KARE394], KARE284, KARE397, KARE409, and KARE221; based on preliminary phylogenetic analyses) and transferred to 90 -mm-diameter petri dishes containing $2 \%$ PDA. Radial growth was measured after 10 days of incubation at $25^{\circ} \mathrm{C}$ in the dark for triplicate plates per isolate by taking two measurements at right angles to one another. The experiment was repeated once. Assessments of colony color (Rayner 1970) and morphology were made after 10 days on PDA. Conidial dimensions of macro- and microconidia ( $n=30$ per isolate each), phialide dimensions ( $n=20$ per isolate), and chlamydospore dimensions $(n=20$ per isolate) were measured at $\times 400$ (Leica DM500B; Leica Microsystems CMS $\mathrm{GmbH}$ ) from 14-day-old synthetic nutrient agar (SNA) (Nirenberg 1976) cultures incubated at room temperature $\left(24^{\circ} \mathrm{C} \pm 1{ }^{\circ} \mathrm{C}\right)$ and ambient fluorescent lighting $(\sim 12 \mathrm{~h}$ of light $/ 12 \mathrm{~h}$ of dark); no stain was applied to preserve the natural fungal pigments. Micromorphological measurements are represented by the mean in the center, with minima and maxima in parentheses, below.

Pathogenicity studies. An in vitro pathogenicity test (Experiment 1) on detached pistachio twigs was conducted in the laboratory to determine the ability of various Fusarium-like spp. to colonize pistachio stems and produce rot or canker symptoms. Experiment 1 was conducted using a selection of Fusarium-like spp. from symptomatic pistachio rootstocks based on phylogenetic results: Neocosmospora solani (Mart) L Lombard \& Crous (syn: Fusarium solani [Mart] Sacc; isolate KARE221), Neocosmospora falciformis (Carrión) L. Lombard \& Crous (syn: Fusarium falciforme [Carrión] Summerb \& Schroers; isolate KARE409), Fusarium oxysporum Schltdl. (isolates KARE266 and KARE397), Fusarium proliferatum (Matsush) Nirenberg (isolates KARE394 and KARE396), and Fusarium equiseti (Corda) Sacc (isolates KARE284 and KARE421) as well as reference isolate RBH3 of $F$. oxysporum $\mathrm{f}$. sp. vasinfectum (GF Atk) WC Snyder \& HN Hansen race 4 isolated from cotton. Two-yearold lignified twigs of each of 'Kerman' (scion cultivar), UCBI (Pistacia atlantica $\times$ Pistacia integerrima), and PGI $(\mathrm{PGI}=P$. integerrima) were harvested from mature trees growing in the field at KARE. Twigs were cut to $20-\mathrm{cm}$ segments, submerged for 4 min in $0.5 \%$ sodium hypochlorite, and rinsed twice in sterile water before inoculation. The outer bark of twigs ( $n=10$ twigs per fungal treatment) was removed using a sterile 5 -mm cork borer, and a mycelial plug taken from the margin of a 7-day-old colony cultured on PDA was inserted into the wound and wrapped with parafilm. Inoculations with sterile PDA plugs served as negative controls. Inoculated twigs were incubated in the laboratory at $25^{\circ} \mathrm{C}$ for 1 month. The length of wood discoloration (LWD) was then measured upward and downward from the point of inoculation. Wood pieces $(4 \times 4 \times 5 \mathrm{~mm})$ taken from the margin of developing cankers were submerged for $2 \mathrm{~min}$ in $0.5 \%$ sodium hypochlorite, rinsed twice with sterile water, and then, placed on APDA for reisolation of the fungus. Recovered fungal isolates were identified based on colony morphological comparisons of the tested fungi and resequencing of the TEF1 locus to fulfill Koch's postulates.

Experiment 2 was conducted on 14 July and repeated on $31 \mathrm{Au}-$ gust of 2016 (Experiment 3) to evaluate the ability of Fusarium-like spp. to cause crown rot or stem cankers in potted 2-year-old clonal UCBI pistachio rootstocks using the same inoculation methodology 
as in Experiment 1. In total, 50 clonal UCBI trees were wound inoculated. These included five replicate plants for each of the nine different Fusarium-like isolates and a control. Plants were examined for symptoms after 16- and 10-week incubation periods. The extent of rot and vascular discoloration developing along the stems was measured up and down from the point of inoculation. Reisolation of the inoculated fungi and confirmation of species identity were conducted as described above.

Lesion length data satisfied the assumptions of normality and homogeneity of variance required for analysis of variance (ANOVA)

Table 1. Fusarium and Neocosmospora spp. isolated from symptomatic UCBI pistachio rootstocks in this study and used in phylogenetic analyses and/or pathogenicity tests, including species utilized for phylogenetic reference ${ }^{\mathrm{w}}$

\begin{tabular}{|c|c|c|c|c|c|c|c|}
\hline \multirow[b]{2}{*}{ Species } & \multirow[b]{2}{*}{ Isolate } & \multirow[b]{2}{*}{ Origin } & \multirow[b]{2}{*}{ Location $^{x}$} & \multicolumn{4}{|c|}{ GenBank accession numbers ${ }^{y}$} \\
\hline & & & & TEF1 & $R P B 2$ & $R P B 2(5 f 2 / 7 \mathrm{cr})$ & $R P B 2(7 \mathrm{cf} / 11 \mathrm{ar})$ \\
\hline Cyanonectria buxi & CBS 12551 & Buxus sempervirens & Slovenia & HQ728150 & HM626690 & - & - \\
\hline Cyanonectria buxi & BBA 64985 & Buxus sempervirens & The Netherlands & HQ728151 & HQ897746 & - & - \\
\hline Fusarium annanatum & NRRL 53131 & Human finger & Italy & HM347128 & HM347213 & - & - \\
\hline Fusarium equiseti & NRRL 13405 & Sweet corn & Pennsylvania, U.S.A. & GQ915507 & GQ915491 & - & - \\
\hline Fusarium equiseti & NRRL 25795 & $\begin{array}{l}\text { Seed of Disphyma } \\
\text { crassifolium }\end{array}$ & Germany & GQ505597 & GQ505775 & - & - \\
\hline Fusarium equiseti & KARE284 & Stem canker & Merced, CA & MK077075 & - & MK077113 & MK077037 \\
\hline Fusarium equiseti & KARE419 & Stem canker & Fresno, CA & MK077072 & - & MK077110 & MK077034 \\
\hline Fusarium equiseti & KARE420 & Stem canker & Fresno, CA & MK077073 & - & MK077111 & MK077035 \\
\hline Fusarium equiseti & KARE421 & Stem canker & Fresno, CA & MK077074 & - & MK077112 & MK077036 \\
\hline Fusarium oxysporum & NRRL 43539 & $\begin{array}{l}\text { Centers for } \\
\text { Disease Control }\end{array}$ & Georgia, U.S.A. & DQ790508 & DQ790596 & - & - \\
\hline Fusarium oxysporum & KARE262 & Stem canker & Madera, CA & MK077056 & - & MK077094 & MK077018 \\
\hline Fusarium oxysporum & KARE263 & Stem canker & Madera, CA & MK077057 & - & MK077095 & MK077019 \\
\hline Fusarium oxysporum & KARE266 ${ }^{\mathrm{z}}$ & Branch canker & Kern, CA & MK077059 & - & MK077097 & MK077021 \\
\hline Fusarium oxysporum & KARE283z & Root lesion & Merced, CA & MK077060 & - & MK077098 & MK077022 \\
\hline Fusarium oxysporum & KARE323 & Branch canker & Madera, CA & MK077061 & - & MK077099 & MK077023 \\
\hline Fusarium oxysporum & KARE397 & Crown rot & Merced, CA & MK077067 & - & MK077105 & MK077029 \\
\hline Fusarium oxysporum & KARE401 & Crown rot & Merced, CA & MK077068 & - & MK077106 & MK077030 \\
\hline Fusarium oxysporum & KARE402 & Crown rot & Merced, CA & MK077062 & - & MK077100 & MK077024 \\
\hline Fusarium oxysporum & KARE403 & Crown rot & Merced, CA & MK077058 & - & МК077096 & MK077020 \\
\hline Fusarium oxysporum & KARE404 & Crown rot & Merced, CA & MK077063 & - & MK077101 & MK077025 \\
\hline Fusarium oxysporum & KARE410 & Crown rot & Merced, CA & MK077064 & - & MK077102 & MK077026 \\
\hline Fusarium oxysporum & KARE1422 & Crown rot & Kern, CA & MK077066 & - & MK077104 & MK077028 \\
\hline Fusarium oxysporum & KARE1424 & Root lesion & Kern, CA & MK077065 & - & MK077103 & MK077027 \\
\hline Fusarium oxysporum & $\mathrm{RBH} 3$ & Cotton & California, U.S.A. & MK138386 & - & MK138387 & MK138388 \\
\hline Fusarium proliferatum & NRRL 54994 & Unknown & Unknown & KC 808226 & КC808369 & - & - \\
\hline Fusarium proliferatum & KARE394z & Crown rot & Merced, CA & MK077069 & - & MK077107 & MK077031 \\
\hline Fusarium proliferatum & KARE395 & Crown rot & Merced, CA & MK077070 & - & MK077108 & MK077032 \\
\hline Fusarium proliferatum & KARE396 $6^{\mathrm{z}}$ & Crown rot & Merced, CA & MK077071 & - & MK077109 & MK077033 \\
\hline Neocosmospora ensiforme & NRRL 28009 & Human eye & Texas, U.S.A. & DQ246869 & EF470136 & - & - \\
\hline Neocosmospora ensiforme & NRRL 32792 & Human & Japan & DQ247101 & EU329621 & - & - \\
\hline Neocosmospora falciformis & NRRL 43441 & Human eye & Pennsylvania, U.S.A. & DQ790478 & DQ790566 & - & - \\
\hline Neocosmospora falciformis & NRRL 43537 & Human eye & Florida, U.S.A. & DQ790506 & DQ790594 & - & - \\
\hline Neocosmospora falciformis & NRRL 32786 & Human eye & Texas, U.S.A. & DQ247095 & FJ240398 & - & - \\
\hline Neocosmospora falciformis & KARE405 & Crown rot & Merced, CA & MK077043 & - & MK077081 & MK077005 \\
\hline Neocosmospora falciformis & KARE406 & Crown rot & Merced, CA & MK077044 & - & MK077082 & MK077006 \\
\hline Neocosmospora falciformis & KARE408 & Crown rot & Merced, CA & MK077045 & - & MK077083 & MK077007 \\
\hline Neocosmospora falciformis & KARE409 & Crown rot & Merced, CA & MK077046 & - & MK077084 & MK077008 \\
\hline Neocosmospora falciformis & KARE1169 & Crown rot & Fresno, CA & MK077047 & - & MK077085 & MK077009 \\
\hline Neocosmospora falciformis & KARE1171 & Crown rot & Fresno, CA & MK077048 & - & MK077086 & MK077010 \\
\hline Neocosmospora falciformis & KARE1419 & Crown rot & Kern, CA & MK077049 & - & MK077087 & MK077011 \\
\hline Neocosmospora falciformis & KARE1421 & Root rot & Kern, CA & MK077050 & - & MK077088 & MK077012 \\
\hline Neocosmospora falciformis & KARE1423 & Root lesion & Kern, CA & MK077051 & - & MK077089 & MK077013 \\
\hline Neocosmospora falciformis & KARE1425 & Root lesion & Kern, CA & MK077052 & - & MK077090 & MK077014 \\
\hline Neocosmospora falciformis & KARE1426 & Root lesion & Kern, CA & MK077053 & - & MK077091 & MK077015 \\
\hline Neocosmospora falciformis & KARE1453 & Crown rot & Fresno, CA & MK077054 & - & MK077092 & MK077016 \\
\hline Neocosmospora falciformis & KARE1454 & Crown rot & Fresno, CA & MK077055 & - & MK077093 & MK077017 \\
\hline Neocosmospora solani & NRRL 66304 & $\begin{array}{l}\text { Decayed Solanum } \\
\text { tuberosum }\end{array}$ & Slovenia & KT313611 & KT313623 & - & - \\
\hline Neocosmospora solani & NRRL 32762 & Human eye & Indiana, U.S.A. & DQ247079 & FJ240407 & - & - \\
\hline Neocosmospora solani & KARE $221^{z}$ & Stem canker & Kern, CA & MK077042 & $\frac{-}{20}$ & MK077080 & MK077004 \\
\hline Neocosmospora solani & KARE233 & Stem canker & Kern, CA & MK077039 & - & MK077077 & MK077001 \\
\hline Neocosmospora solani & KARE398 & Crown rot & Merced, CA & MK077040 & - & MK077078 & MK077002 \\
\hline Neocosmospora solani & KARE399 & Crown rot & Merced, CA & MK077041 & - & MK077079 & MK077003 \\
\hline Neocosmospora solani & KARE1420 & Root rot & Kern, CA & MK077038 & - & MK077076 & MK077000 \\
\hline
\end{tabular}

${ }^{\mathrm{w}}$ KARE, Kearney Agricultural Research and Extension; RPB2, second largest subunit of RNA polymerase II; TEF1, translation elongation factor 1- $\alpha$.

${ }^{x}$ Counties in California, U.S.A.

y Sequences in bold were generated in this study.

${ }^{\mathrm{z}}$ Isolates used in pathogenicity tests on Pistacia vera in this study. 
according to Shapiro-Wilk's and Bartlett's tests, respectively. ANOVAs were performed in Statistix 10 (Analytical Software) to evaluate differences in the LWD between the control and fungal treatments. To assess the effect of isolate on lesion length in each experiment, ANOVA and Tukey's tests were performed.

\section{Results}

Disease symptoms and origin of fungal isolates. Several unbudded 1-year-old clonal UCBI rootstocks showing chlorotic foliage (Fig. 1A) in combination with crown rot symptoms (Fig. 1B) were observed in four orchards in Kern County. Tree death also occurred in these orchards. In other instances, 6- to 10-year-old trees in Fresno and Merced Counties were observed with crown rot symptoms extending from below the soil line and up into the trunk. The phloem and bark tissues were killed as revealed by a dark discoloration of cambial tissues just below the outer bark (Fig. 1C). Other symptoms included poor vigor, leaf chlorosis, and light-colored gumming on the lower portion of the trunk. Additional trees displayed cankers, wood discolorations, and lesions that developed near sites of injury caused by cultivation equipment or mechanical harvesters on the stem of pistachio rootstocks (Fig. 1D). Fusarium-like species were the main fungi isolated from these various symptomatic tissues on pistachio rootstocks, and 38 isolates were obtained and permanently preserved in the collections of the Department of Plant Pathology at KARE (Table 1).

Phylogenetic analyses and fungal identifications. For the ML analysis, the best-fit model of nucleotide substitution was deduced based on the AIC (general time reversible [GTR] + gamma distribution [G]). Alignment of two Cyanonectria, 26 Fusarium, and $26 \mathrm{Neo}$ cosmospora sequences resulted in a 2,585-character dataset $(1,746$ characters were constant, 756 characters were parsimony informative, and 83 characters were parsimony uninformative). MP analysis produced the 100 equally most parsimonious trees of 1,301 steps and

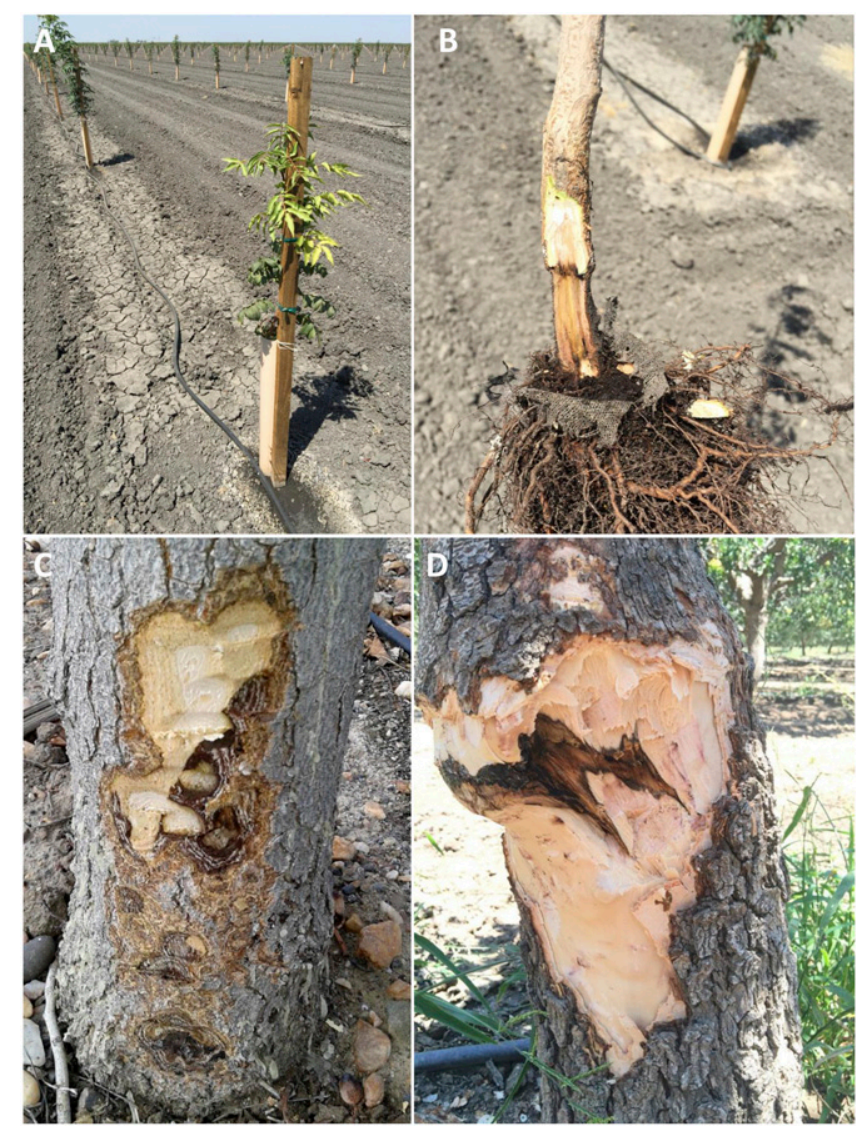

Fig. 1. Symptoms in pistachio rootstocks associated with Fusarium and Neocosmospora spp. A, Wilting in unbudded University of California, Berkeley I pistachio rootstock. B, Associated crown rot symptom. C, Crown rot symptom on mature pistachio tree. D, Injury-associated lesion on the trunk of a pistachio tree. consistency index, retention index, and rescaled consistency index values of $0.808,0.976$, and 0.789 , respectively. MP and ML (ln likelihood -10,277.0209) analyses revealed three species of the genus Fusarium and two species of the genus Neocosmospora (Fig. 2). Thirteen isolates clustered strongly (100/100\%, MP and ML bootstrap values, respectively) with a representative specimen of $F$. oxysporum (NRRL 43539). Two isolates in the $F$. oxysporum clade (KARE397 and KARE401) clustered strongly (100/100\%) with a reference isolate of $F$. oxysporum $\mathrm{f}$. sp. vasinfectum race 4 (isolate RBH3) from cotton. Three isolates strongly clustered (100/100\%) with a representative isolate of $F$. proliferatum (NRRL 54994). Four isolates clustered with representative isolates of $F$. equiseti (NRRL 25795 and NRRL 13405). Eighteen isolates were identified as residing in the genus Neocosmospora. Thirteen isolates were identified as $N$. falciformis, which is the sister to five isolates that cluster strongly with the epitype (NRRL 66304/CBS 140079) of N. solani (syn. F. solani).

Morphology. Morphological characteristics of the fungal isolates recovered from symptomatic pistachio trees were similar to the descriptions of fungi residing in the genera Fusarium and Neocosmospora (Guarnaccia et al. 2018; Leslie and Summerell 2006). F. proliferatum isolate KARE394 colonies after 10 days average $81.2 \mathrm{~mm}$ in diameter on PDA and are off white, with a highly torn margin and abundant floccose aerial hyphae (Fig. 3A and B). On SNA, phialides are smooth, subcylindrical, and arranged as one to three monophialides: $(12.5-) 16.4(-21) \times(2.5-) 3.5(-4.5) \mu \mathrm{m}$. Macroconidia are slender and straight to slightly curved with three to four septa, and end cells are curved: $(24.2-) 34.3(-46.2) \times$ (3.5 -) 4.4 (- 5.5) $\mu \mathrm{m}$ (Fig. 3C). Microconidia are elliptical: (5.4-) $6.5(-8.1) \times(1.4-) 1.9(-2.6) \mu \mathrm{m}$. Chlamydospores are not observed. F. equiseti isolate KARE284 colonies after 10 days average $77.4 \mathrm{~mm}$ in diameter on PDA with slightly uneven margin expansion; the colony center is mostly white with sparse aerial hyphae becoming dark with age (Fig. 3D and E). On SNA, phialides are smooth, subcylindrical, and arranged as one to three monophialides: $(10-) 18.5(-24.2) \times(2.5-) 3.5(-5) \mu \mathrm{m}$. Macroconidia are fusoid, with two to three septa and curved end cells: $(14.4-) 22.5(-30.5) \times$ (4.0 -) $5.1(-6.3) \mu \mathrm{m}$ (Fig. 3F). Microconidia are elliptical: $(6.7-)$ $9.8(-14.4) \times(2.8-) 3.7(-4.3) \mu \mathrm{m}$. Chlamydospores are globose to subglobose: $(6.1-) 7.2(-8.3) \times(5.6-) 8.3(-12.9) \mu \mathrm{m}$; they are mostly smooth, and some appear rough with deposits. They are thick walled and formed singly or more commonly, in short chains of up to four to five, becoming brown with age. F. oxysporum isolate KARE397 colonies after 10 days average $90 \mathrm{~mm}$ in diameter on PDA with even margin expansion, and they are mainly white, with a light purple center and aerial floccose hyphae (Fig. 3G). The bottom of the petri dish was purplish violet, typical of this species (Fig. $3 \mathrm{H}$ ). On SNA, phialides are smooth, subcylindrical, and arranged as one to three monophialides: $(9-) 13.4(-16.2) \times(2.5-) 3.5(-5.5) \mu \mathrm{m}$. Macroconidia are fusoid, with two to three septa and curved end cells: $(19.8-) 29.4(-34.9) \times(3.7-) 4.9(-6.4) \mu \mathrm{m}$ (Fig. 3I). Microconidia are elliptical: $(5.7-) 7.5(-9.7) \times(1.9-) 2.3(-3.4) \mu \mathrm{m}$. Chlamydospores are globose to subglobose: $(6.3-) 7.4(-9) \times(9.7-)$ $11(-13.1) \mu \mathrm{m}$. They are mostly smooth and thick walled, and they are formed singly or more rarely, in pairs, becoming brown with age. $N$. falciformis isolate KARE409 colonies after 10 days average $75.6 \mathrm{~mm}$ in diameter on PDA, with smooth margin and colony expansion; they are mainly white, with the center darkening with age and sparse aerial floccose hyphae (Fig. 3J). The bottom of the petri dish is bright yellowish orange (Fig. 3K). On SNA, phialides are smooth, subcylindrical, and arranged as one to three monophialides: $(12.4-) 17.8(-23.7) \times(2.5-) 3.5(-4.5) \mu \mathrm{m}$. Macroconidia are slightly fusoid, with two to three septa and curved to bent end cells: $(37.7$-) $43.4(-47.2) \times(5.6-) 6.0(-6.5) \mu \mathrm{m}$ (Fig. 3L). Microconidia are elliptical: $(9.1-) 10.4(-13) \times(2.3-) 2.8(-3.3) \mu \mathrm{m}$. Chlamydospores are globose to subglobose: $(6.4-) 7.4(-8.4) \times(6.5-) 8$ $(-10.2) \mu \mathrm{m}$; they are mostly smooth and thick walled, and they are formed singly or in short chains, becoming brown with age. $N$. solani isolate KARE221 colonies after 10 days average $68 \mathrm{~mm}$ in diameter on PDA; they are white, with a smooth margin and even colony 
expansion (Fig. 3M and N). On SNA, phialides are smooth, subcylindrical, and arranged as one to three monophialides: $(10-) 18.5$ $(-24.2) \times(2.5-) 3.5(-5) \mu \mathrm{m}$. Macroconidia are fusoid, with three to four septa and end cells curved to slightly bent upwards: $(33.0-)$ $37.8(-46.9) \times(5.3-) 6.3(-7.6) \mu \mathrm{m}$ (Fig. 3O). Microconidia are elliptical: $(6.5-) 9.5(-12.5) \times(2.3-) 3.1(-4) \mu \mathrm{m}$. Chlamydospores are globose to subglobose: $(4.3-) 6.1(-7.6) \times(5.8-) 7.1(-7.9) \mu \mathrm{m}$; they are mostly smooth (although some appear rough) with deposits and thick walled, and they are formed singly or in short chains of up to three, becoming brown with age.

Pathogenicity studies. In controlled inoculations of 2-year-old detached pistachio twigs (Experiment 1), all Fusarium and Neocosmospora spp. caused lesions in the wood of UCBI and PGI rootstocks as well as in the pistachio cultivar Kerman (Table 2). Symptoms on detached twigs appeared $\sim 3$ weeks after inoculation and consisted of dark brown vascular discolorations (Fig. 4A to C)

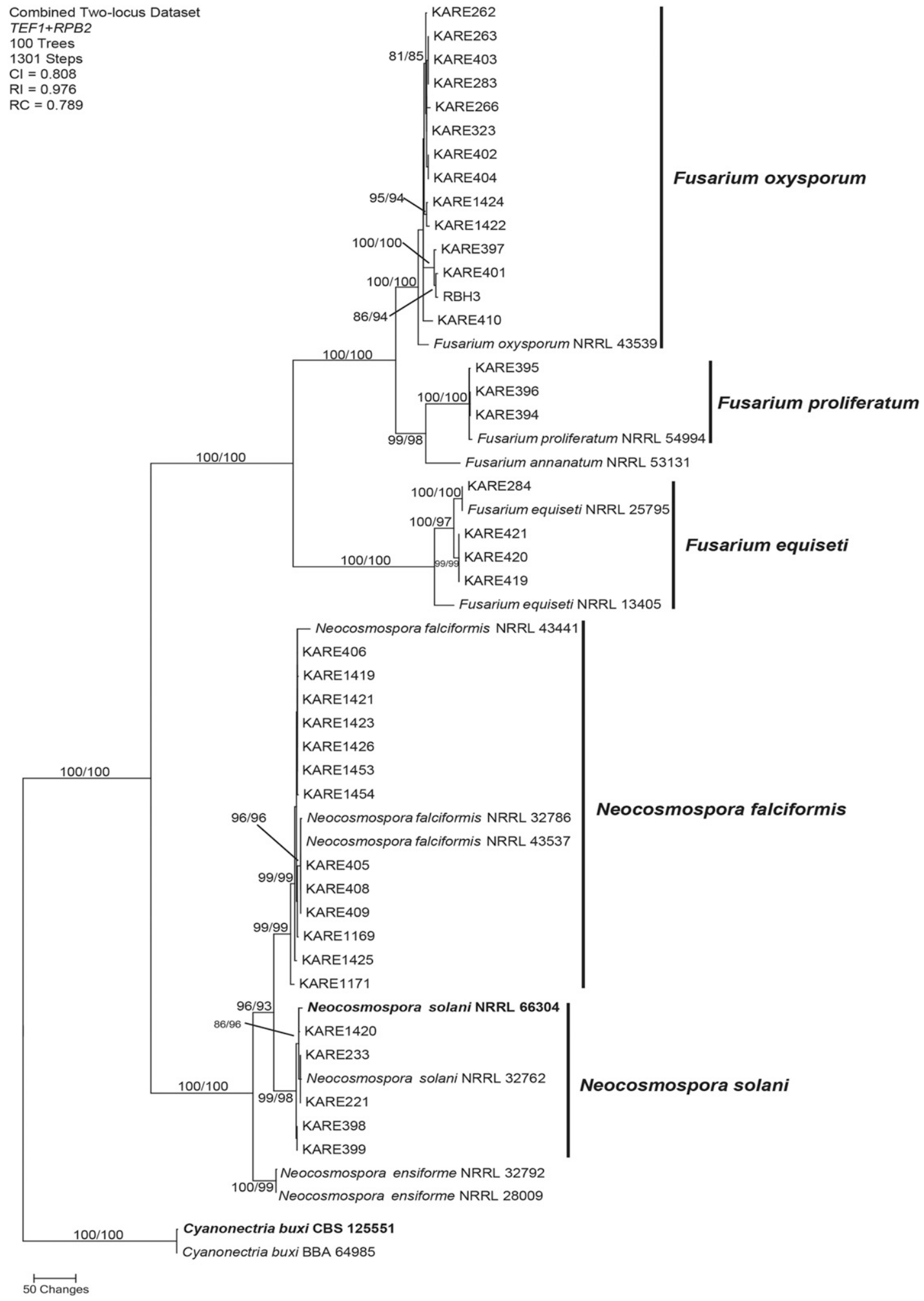

Fig. 2. One of 100 equally most parsimonious trees inferred from maximum parsimony analysis of the two-gene (translation elongation factor 1- $\alpha$ [TEF1] + second largest subunit of RNA polymerase II [RPB2]) combined dataset. Numbers in front and after the slash represent parsimony and likelihood bootstrap values from 1,000 replicates, respectively. The scale bar indicates the number of nucleotide changes. Cl, consistency index; KARE, Kearney Agricultural Research and Extension; RC, rescaled consistency index; RI, retention index. 
ranging from 23.5 to $63.6 \mathrm{~mm}$ among the various Fusarium and Neocosmospora spp. across all rootstocks and 'Kerman' (Table 2). Fusarium and Neocosmospora spp. produced the longest lesions, on average, in UCBI followed by PGI and 'Kerman' (Table 2). Significant differences in virulence were found among the various fungal isolates and within each inoculated rootstock, including PGI $(P<$ $0.0000)$, UCBI $(P<0.0000)$, and 'Kerman' pistachio scion cultivar $(P=0.0327)$. Overall, $F$. oxysporum isolates KARE266 and KARE397 seemed to be the most aggressive followed by $F$. proliferatum isolates KARE394 and KARE396 and $N$. solani isolate KARE221 (Table 2). In some cases, fungal treatments were not significantly different compared with the control treatment (Table 2). For example, lesions caused by $N$. solani in PGI and 'Kerman' were not significantly different than the controls; however, N. solani caused significantly longer lesions in UCBI compared with the control, and these lesions were, on average, longer than all other species tested. The percentage of fungal recovery from the margin of lesions in detached twigs of UCBI, PGI rootstocks, and pistachio 'Kerman' was $100 \%$ for all Fusarium and Neocosmospora spp. tested and confirmed based on colony morphological comparisons and identical TEF 1 resequencing, and not recovered from control plants, thereby fulfilling Koch's postulates.

In the greenhouse pathogenicity assays (Experiments 2 and 3) using mycelial plugs inoculated to potted UCBI clonal rootstocks, lesion and rot symptoms were observed after 16- and 10-week incubation periods, respectively. Symptoms included brown to light brown necrotic lesions that extended longitudinally from the point of inoculation (Fig. 4D to F). F. oxysporum, $N$. solani, $N$. falciformis, and $F$. proliferatum isolates produced lesions that differed significantly among isolates and that were significantly longer than those produced in the mock-inoculated control (Experiment 2: $P<$ 0.0000 and Experiment 3: $P=0.0001$ ). Isolates of $F$. equiseti did not produce lesions that were significantly longer than those produced in the mock-inoculated control, and this species was considered to be nonpathogenic, which was similar to results obtained from Experiment 1, except that $F$. equiseti was mildly pathogenic to detached 2-year-old PGI twigs. In Experiment 2, Fusarium and Neocosmospora spp. produced lesions ranging from 12.6 to 29.8 $\mathrm{mm}$ in length. Lesions averaged $7.8 \mathrm{~mm}$ in the control. In Experiment 3 , lesions ranged from 15.8 to $37 \mathrm{~mm}$ in length for Fusarium and Neocosmospora isolates and averaged $8.2 \mathrm{~mm}$ in the control. In both greenhouse experiments, isolates KARE266 and KARE397 of $F$. oxysporum, isolates KARE394 and KARE396 of $F$. proliferatum, and isolate KARE221 of $N$. solani were the most aggressive to potted UCBI clonal pistachio rootstocks (Fig. 5). Fungi with Fusarium-like asexual morphs were reisolated from developing lesions from 60 to $100 \%$ of the artificially inoculated plants across both experiments and morphologically and molecularly confirmed as above. No Fusarium-like anamorphs were recovered from control plants. Pistachio trees did not show wilt symptoms during the experiments.

\section{Discussion}

This study provides new insights into the biodiversity, taxonomy, and pathogenicity of Fusarium and Neocosmospora spp. associated with crown rot and stem canker of pistachio rootstocks in central California. Fusarium and Neocosmospora spp. isolated in this study were identified based on molecular phylogenetic analyses of the combined alignment of $T E F 1$ and $R P B 2$ gene fragments paired with morphological observations. A total of five species are reported from pistachio trees, with $F$. oxysporum and $N$. falciformis being the most commonly isolated species in central California orchards. To our knowledge, $F$. proliferatum and $N$. falciformis are newly reported fungal associates of pistachio trees. Pathogenicity studies of the various Fusarium and Neocosmospora spp. in potted UCBI pistachio rootstocks revealed that $F$. oxysporum, $F$. proliferatum, and $N$. solani were the most aggressive species. The same fungi were reported as
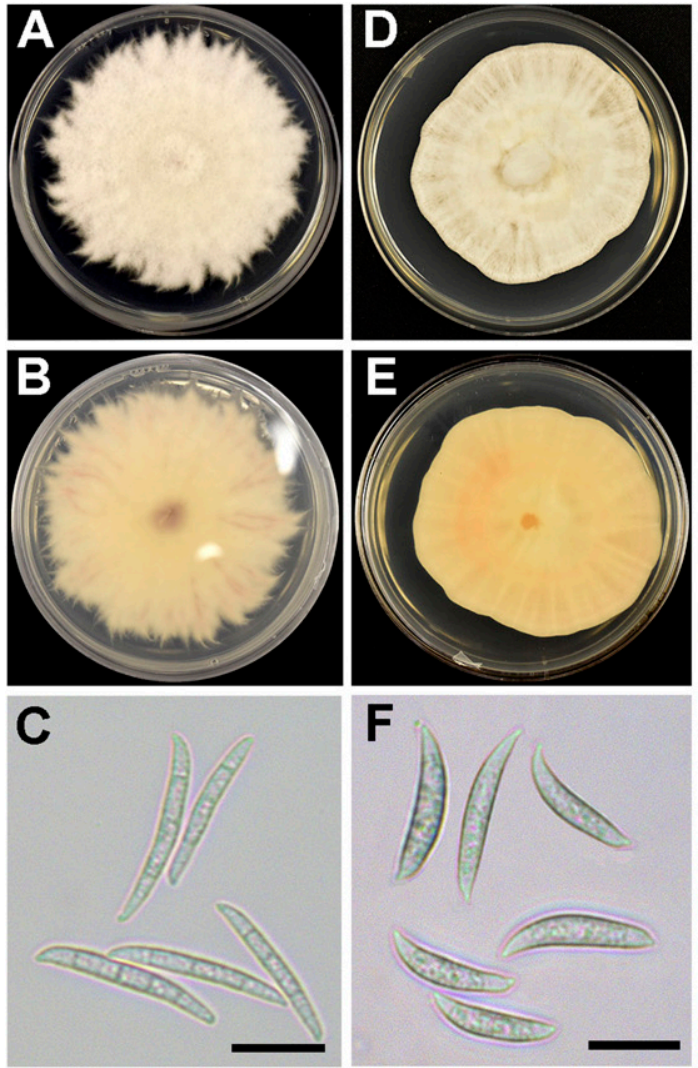
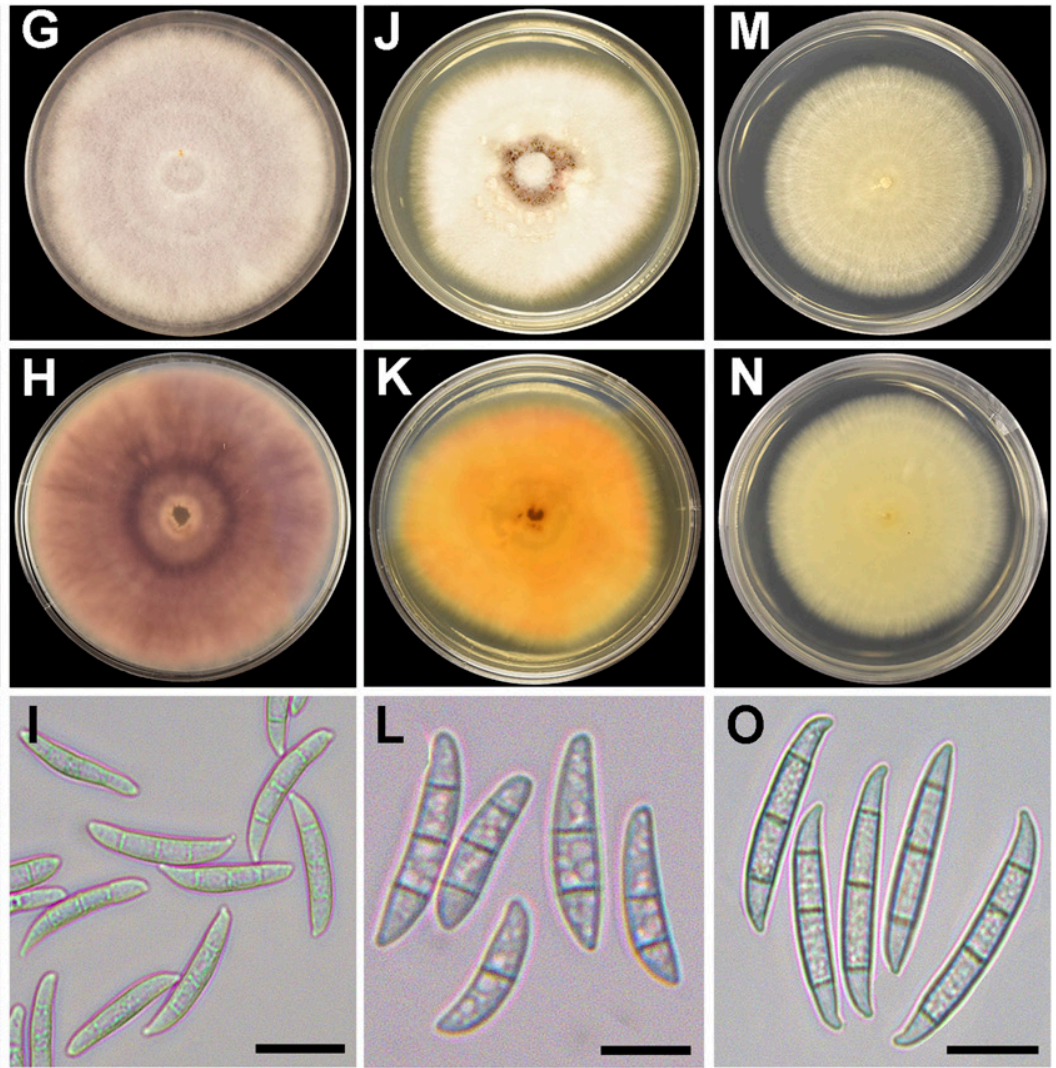

Fig. 3. Morphological characterization of fungal isolates of A, Fusarium proliferatum Kearney Agricultural Research and Extension (KARE) 394 (KARE394; top), B, F. proliferatum KARE394 (bottom), C, F. proliferatum KARE394 macroconidia, D, Fusarium equiseti KARE284 (top), E, F. equiseti KARE284 (bottom), F, F. equiseti KARE284 macroconidia, G, Fusarium oxysporum KARE397 (top), H, F. oxysporum KARE397 (bottom), I, F. oxysporum KARE397 macroconidia, J, Neocosmospora falciformis KARE409 (top), K, N. falciformis KARE409 (bottom), L, N. falciformis KARE409 macroconidia, M, Neocosmospora solani KARE221 (top), N, N. solani KARE221 (bottom), and O, N. solani KARE221 macroconidia. 
canker and dry root rot pathogens of citrus trees in Greece, Italy, and Spain (Sandoval-Denis et al. 2018). F. equiseti inoculations resulted in small lesions that were not significant compared with control plant lesions, suggesting that this species is a saprobe that is capable of colonizing diseased pistachio tissues. F. equiseti is known as a common colonizer of senescing or damaged plant tissues, and it is considered generally to be a weak pathogen (Leslie and Summerell 2006).

Fusarium spp. include many important plant pathogens, with some species being pathogenic on a broad range of host plants (generalists), whereas other species are specialized, causing diseases to a limited number of plant species (specialists) (Leslie and Summerell 2006). The genus Neocosmospora includes a well-recognized group of plant, human, and animal pathogens previously assigned to the $F$. solani species complex and is mainly characterized by forming yellow-, orange-, or red brown-colored perithecial sexual morphs, producing aseptate or 1-septate, globose to ellipsoidal, finely striate ascospores (Sandoval-Denis et al. 2018). Many members of the former F. solani species complex (now $N$. solani) are known to cause severe crown and root rots of a wide array of herbaceous plants, such as peas, beans, tomatoes, and tuber roots (Leslie and Summerell

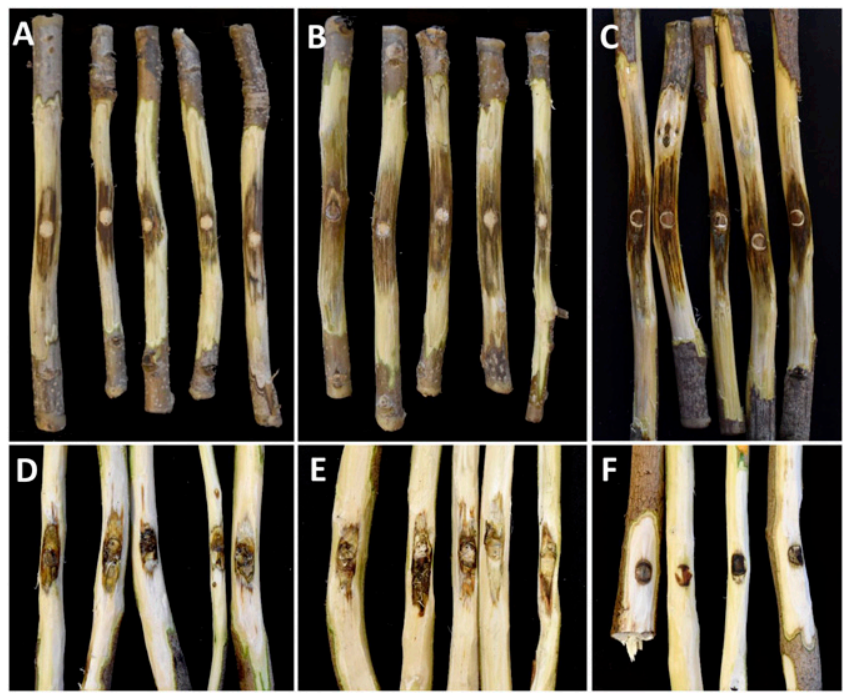

Fig. 4. Symptoms produced after inoculation in detached twigs (Experiment 1) of $\mathbf{A}$, Fusarium proliferatum Kearney Agricultural Research and Extension 396 (KARE396) in Pioneer Gold I rootstock, B, F. proliferatum KARE397 in University of California, Berkeley I (UCBI) clonal rootstock, and C, F. proliferatum KARE396 in Pistacia vera 'Kerman.' Symptoms produced after inoculation in UCBI clonal potted plants (Experiment 2) with D, Neocosmospora falciformis KARE409, E, Fusarium oxysporum RBH3, and $\mathbf{F}$, the mock-inoculated control.
2006). F. oxysporum is generally associated with vascular wilt and root diseases on a wide range of plants (Leslie and Summerell 2006; Nelson et al. 1981). Plant pathogenic isolates of $F$. oxysporum can be separated into formae speciales based on their pathogenicity to one or more host plants. For example, $F$. oxysporum f. sp. vasinfectum is a polyphyletic group composed of six races (Cianchetta et al. 2015; Skovgaard et al. 2001) that cause wilt of cotton in the San Joaquin Valley of California, which may result in serious economic losses (Kim et al. 2005). Two isolates of $F$. oxysporum from pistachio (KARE401 and KARE397) seemed to be closely related to a reference isolate of $F$. oxysporum f. sp. vasinfectum race 4 (isolate $\mathrm{RBH} 3$ ) from cotton; however, additional multilocus sampling or the use of specific markers will be needed to refine this relationship further owing to the polyphyletic nature of $F$. oxysporum $\mathrm{f}$. sp. vasinfectum race 4 . In California, pistachio trees are commonly planted after cotton, and the possibility of cross-infection of $F$. oxysporum $\mathrm{f}$. sp. vasinfectum was questioned. Although isolate $\mathrm{RBH} 3$ (including KARE397) produced canker lesions in artificially inoculated pistachio trees, this formae speciales, to our knowledge, has not been isolated from diseased pistachio trees in the field and is only known to be pathogenic to susceptible cotton cultivars. Additional studies will be required to more fully examine this interesting finding.

Only a few Fusarium spp. are known to cause crown rot and canker diseases in woody plants. $F$. solani s. lat. has been reported to cause dry rot of citrus in California and Texas (Adsemoye et al. 2011; Kunta et al. 2015), and it has been shown to cause root rot of pistachio trees in Tunisia (Triki et al. 2009). In 2018, SandovalDenis et al. (2018) reported a broad diversity of Fusarium-like species (six Fusarium spp. and five Neocosmospora spp.) isolated from dry root rot, crown, trunk, or twig cankers or twig dieback of citrus trees in Greece, Italy, and Spain. The most commonly isolated species from Citrus hosts included F. oxysporum, Fusarium sarcochroum (Desm) Sacc, and N. solani (Sandoval-Denis et al. 2018). Neocosmospora perseae Sand-Den \& Guarnaccia was described from symptomatic trunks of avocado trees in Italy, and its pathogenicity to this host as a canker pathogen was confirmed (Guarnaccia et al. 2018). Most prominent in herbaceous plants, however, F. oxysporum has been described as a canker pathogen of the Phoenix tree (Firmiana simplex) in China (Zhang et al. 2013) and a root and crown rot pathogen of sweet cherry (Prunus avium) in British Columbia (Urbez-Torres et al. 2016). F. equiseti has been associated with root and crown rot of pistachio in the eastern Mediterranean and southeast Anatolian regions (Eskalen et al. 2001). Fusarium acuminatum Ellis \& Everh, Fusarium avenaceum (Fr) Sacc, and N. solani (syn: Fusarium solani) were found to produce lesions on almond tree segments (Marek et al. 2013). These pathogens were apparently associated with severe canker disease affecting almond trees and other fruit trees during cold storage of dormant trees in California (Marek et al.

Table 2. Average lesion length in 2-year-old detached twigs of University of California, Berkeley I (UCBI) clonal and Pioneer Gold I (PGI) rootstocks and Pistacia vera 'Kerman' 1 month postinoculation with Fusarium and Neocosmospora species using mycelial plugs

\begin{tabular}{|c|c|c|c|c|c|}
\hline \multirow[b]{2}{*}{ Species } & \multirow[b]{2}{*}{ Isolate $^{\mathrm{y}}$} & \multicolumn{3}{|c|}{ Lesion length by cultivar (mm) } & \multirow[b]{2}{*}{ Average } \\
\hline & & PGI $^{\mathbf{z}}$ & P. vera ${ }^{\mathrm{z}}$ & $\mathbf{U C B I}^{\mathbf{z}}$ & \\
\hline Fusarium oxysporum & KARE266 & $49.4 \mathrm{a}$ & $29.5 \mathrm{ab}$ & $60.2 \mathrm{a}$ & 46.4 \\
\hline Fusarium oxysporum & KARE397 & $47.1 \mathrm{a}$ & $35.1 \mathrm{ab}$ & $54.8 \mathrm{ab}$ & 45.7 \\
\hline Fusarium oxysporum f. sp. vasinfectum & RBH3 & $30.1 \mathrm{abc}$ & $33.0 \mathrm{ab}$ & $23.5 \mathrm{~cd}$ & 28.9 \\
\hline Fusarium proliferatum & KARE394 & $34.8 \mathrm{ab}$ & $32.9 \mathrm{ab}$ & $57.5 \mathrm{ab}$ & 41.7 \\
\hline Fusarium proliferatum & KARE396 & $37.0 \mathrm{ab}$ & $40.6 \mathrm{a}$ & $43.9 \mathrm{abc}$ & 40.5 \\
\hline Fusarium equiseti & KARE421 & $34.2 \mathrm{ab}$ & $27.4 \mathrm{ab}$ & $29.3 \mathrm{~cd}$ & 30.3 \\
\hline Fusarium equiseti & KARE284 & $43.1 \mathrm{ab}$ & $25.3 \mathrm{ab}$ & 35.8 abcd & 34.7 \\
\hline Neocosmospora solani & KARE221 & $25.3 \mathrm{bc}$ & $31.5 \mathrm{ab}$ & $63.6 \mathrm{a}$ & 40.1 \\
\hline Neocosmospora falciforme & KARE409 & $41.2 \mathrm{ab}$ & $34.5 \mathrm{ab}$ & $29.1 \mathrm{bcd}$ & 34.9 \\
\hline Average & & 38.0 & 32.2 & 44.2 & \\
\hline Control & & $10.7 \mathrm{c}$ & $15.4 \mathrm{~b}$ & $10.6 \mathrm{~d}$ & 12.2 \\
\hline
\end{tabular}

y KARE, Kearney Agricultural Research and Extension.

${ }^{\mathrm{z}}$ Means followed by different letters represent significant differences according to Dunn's test $(P<0.05)$. 
2013). Main symptoms included necrosis of the inner bark, cambium, and sapwood, and it commonly occurred at the graft union, spreading to both the scion and the rootstock (Marek et al. 2013). Finally, several Fusarium spp. have been associated also with cankers and dieback diseases of trees (Bloomberg 1981; Eskalen et al. 2013; Graham et al. 1985; Leslie and Summerell 2006; Lombard et al. 2008; Nelson et al. 1981).

More attention has been given to Fusarium and Neocosmospora spp. as severe canker, dieback, and rot pathogens of trees, where traditionally, they have been considered as secondary colonizers of diseased tissues as well as facultative pathogens of stressed trees. Association of these fungi with Phytophthora root and crown rots is generally common as well as with trees suffering grafting incompatibility, poor drainage, drought stress, excess fertilizer, or altered soil $\mathrm{pH}$ (Menge 1988). With California facing severe episodes of drought, pistachio trees that suffer from hydraulic stress may become more susceptible to opportunistic Fusarium/Neocosmospora pathogens. Many canker-causing agents are also facultative/opportunistic pathogens that readily invade a weakened host but rarely affect vigorous trees (Nemec 1987). There is evidence that environmental stress may predispose woody plants to diseases (Schoeneweiss 1981). Previous work has shown that drought stress can enhance the proliferation and spread of Fusarium pathogens in barley after the initial infection phase (Liu and Liu 2016). As the pistachio industry expands, more rootstocks are being planted in marginal grounds and irrigated with saline water. This may result in greater stress in pistachio trees, rendering them more susceptible to attack by Fusarium/Neocosmospora spp. Additional work is needed to better understand the role of abiotic factors and other stresses in intensifying Fusarium/Neocosmospora diseases associated with pistachio in California.

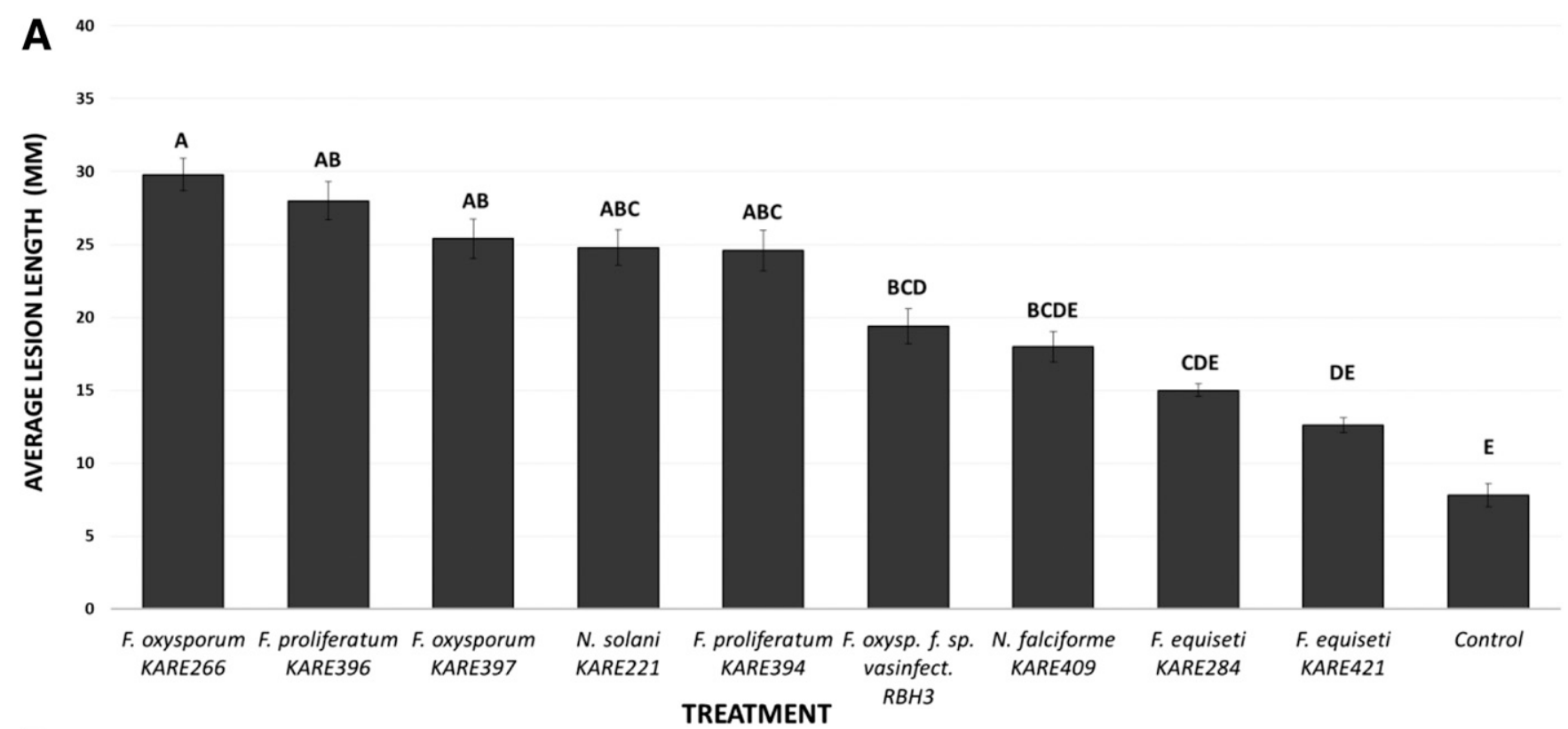

B

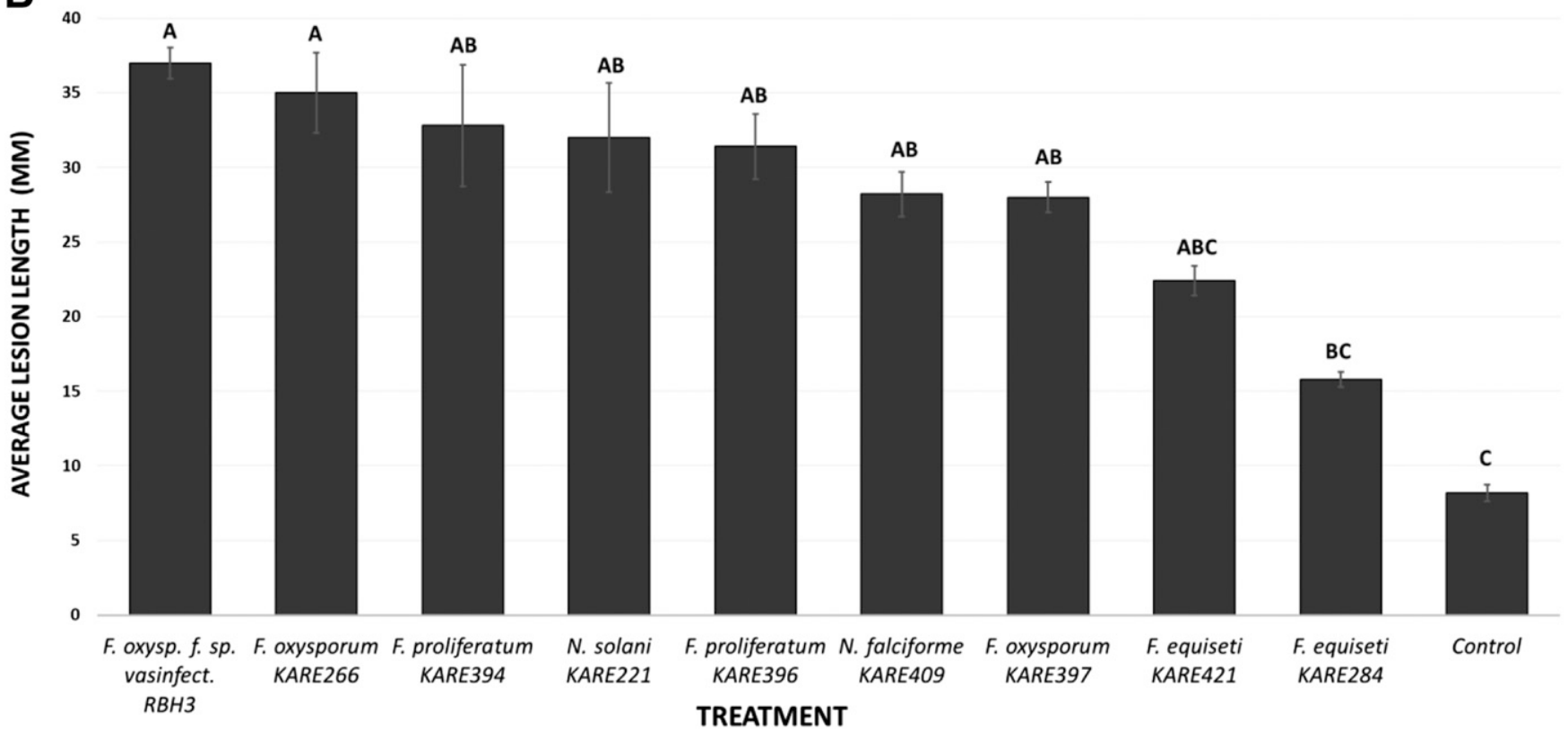

Fig. 5. Mean lesion lengths (millimeters) on pistachio cultivar University of California, Berkeley I (UCBI) rootstock inoculated with Fusarium isolates (Fusarium equiseti, Fusarium oxysporum, and Fusarium proliferatum) and Neocosmospora isolates (Neocosmospora falciformis and Neocosmospora solani) after 16 and 10 weeks for A, Experiment 2 and B, Experiment 3, respectively. Each treatment consisted of five replicates per experiment per replicate experiment. Error bars represent standard error. Different letters represent significant differences according to Tukey's honestly significant difference (HSD) $(P<0.05)$; each experiment was analyzed independently. KARE, Kearney Agricultural Research and Extension. 
In conclusion, this study identified three Fusarium spp. and two Neocosmospora spp. originating from crown rot and stem canker symptoms of pistachio rootstocks in California. F. oxysporum, $F$. proliferatum, $N$. solani, and $N$. falciformis caused rot in pistachio expressed as extensive lesions and vascular discolorations within a few months after inoculation. These species were pathogenic to clonal UCBI rootstock, the most widely planted pistachio rootstock in California. Current work in our laboratory is investigating the relative susceptibility of pistachios to pathogenic Fusarium/Neocosmospora spp. to identify the most tolerant rootstocks and provide sustainable disease management strategies for the pistachio industry of California.

\section{Literature Cited}

Adsemoye, A., Eskalen, A., Faber, B., Bender, G., O'Connell, N., Kallsen, C., and Shea, T. 2011. Current knowledge on Fusarium dry rot of citrus. Citrograph 2: 29-33.

Bloomberg, W. J. 1981. Diseases caused by Fusarium in forest nurseries. Pages 178-187 in: Fusarium: Diseases, Biology, and Taxonomy. P. E. Nelson, T. A. Tousson, and R. J. Cook, eds. Pennsylvania State University Press, University Park, PA.

Cianchetta, A. N., Allen, T. W., Hutmacher, R. B., Kemerait, R. C., Kirkpatrick, T. L., Lawrence, G. W., Lawrence, K. S., Mueller, J. D., Nichols, R. L., Olsen, M. W., Overstreet, C., Woodward, J. E., and Davis, R. M. 2015. Survey of Fusarium oxysporum f. sp. vasinfectum in the United States. J. Cotton Sci. 19:328-336.

Erwin, D. C., and Ribeiro, O. K. 1996. Phytophthora Diseases Worldwide. American Phytopathological Society Press, St. Paul, MN.

Eskalen, A., Küsek, M., Danisti, L., and Karadag, S. 2001. Fungal diseases in pistachio trees in East-Mediterranean and Southeast Anatolian regions. Pages 261-264 in: XI GREMPA Seminar on Pistachios and Almonds. B. E. Ak, ed. Cahiers Options Méditerranéennes.

Eskalen, A., Stouthamer, R., Lynch, S. C., Rugman-Jones, P. F., Twizeyimana, M., Gonzalez, A., and Thibault, T. 2013. Host range of Fusarium dieback and its ambrosia beetle (Coleoptera: Scolytinae) vector in Southern California. Plant Dis. 97:938-951

Fichtner, E. J., Browne, G. T., Mortaz, M., Ferguson, L., and Blomquist, C. L. 2016a. First report of root rot caused by Phytopythium helicoides on pistachio rootstock in California. Plant Dis. 100:2337.

Fichtner, E. J., Kallsen, C. E., and Blomquist, C. L. 2016b. First report of crown rot caused by Phytophthora parsiana on pistachio in the southern San Joaquin Valley, California. Plant Dis. 100:1795.

Geiser, D. M., Jimenez-Gasco, M., Kang, S., Makalowska, I., Veeraraghavan, N., Ward, T. J., Zhang, N., Kuldau, G. A., and O'Donnell, K. 2004. FUSARIUMID v.1.0: A DNA sequence database for identifying Fusarium. Eur. J. Plant Pathol. 110:473-479.

Geisseler, D., and Howarth, W. R. 2016. Pistachio Production in California. https:// apps1.cdfa.ca.gov/FertilizerResearch/docs/Pistachio_Production_CA.pdf

Graham, J. H., Brlansky, R. H., Timmer, L. W., Lee, R. F., Marais, L. J., and Bender, G. S. 1985. Comparison of citrus tree declines with necrosis of major roots and their association with Fusarium solani. Plant Dis. 69:1055-1058.

Guarnaccia, V., Sandoval-Denis, M., Aiello, D., Polizzi, G., and Crous, P. W. 2018. Neocosmospora perseae sp. nov., causing trunk cankers on avocado in Italy. Fun. Syst. Evol. 1:131-140.

Holtz, B. A., and Teviotdale, B. L. 2016. Soil-borne diseases. Pages 257-264 in: Pistachio Production Manual. L. Ferguson and D. Haviland, eds. University of California Agriculture and Natural Resources, Oakland, CA.

Kim, Y., Hutmacher, R. B., and Davis, R. M. 2005. Characterization of California isolates of Fusarium oxysporum f. sp. vasinfectum. Plant Dis. 89:366-372.

Kunta, M., Salas, B., Gonzales, M., and da Graça, J. V. 2015. First report on citrus dry rot in sour orange rootstock in Texas. J. Citrus Pathol. 2:1-5.

Leslie, J. F., and Summerell, B. A., eds. 2006. The Fusarium Laboratory Manual. Blackwell Publishing, Oxford, United Kingdom.

Liu, X., and Liu, C. 2016. Effects of drought-stress on Fusarium crown rot development in barley. PLoS One 11:e0167304.
Liu, Y. J., Whelen, S., and Hall, B. D. 1999. Phylogenetic relationships among ascomycetes: evidence from an RNA polymerse II subunit. Mol. Biol. Evol. 16:1799-1808

Lombard, L., Bogale, M., Montenegro, F., Wingfield, B. D., and Wingfield, M. J. 2008. A new bark canker disease of the tropical hardwood tree Cedrelinga cateniformis in Ecuador. Fungal Divers. 31:73-81.

MacDonald, J. D., Banihashemi, Z., Mircetich, S. M., Browne, G., and Bolkan, L. 1992. Trunk and branch canker of pistachio caused by Phytophthora spp. Phytopathology 82:1089.

Maddison, W. P., and Maddison, D. R. 2016. Mesquite: A Modular System for Evolutionary Analysis. Version 3.10. http://www.mesquiteproject.org/

Marek, S. M., Yaghmour, M. A., and Bostock, R. M. 2013. Fusarium spp. Cylindrocarpon spp., and environmental stress in the etiology of a canker disease of cold-stored fruit and nut tree seedlings in California. Plant Dis. 97:259-270.

Menge, J. A. 1988. Dry root rot. Pages 14-15 in: Compendium of Citrus Diseases. J. O. Whiteside, S. M. Garnsey, and L. W. Timmer, eds. APS Press, St. Paul, MN

Michailides, T. J. 2005. Pest, Disease, and Physiological Disorders Management: Above Ground Fungal Diseases. http://fruitsandnuts.ucdavis.edu/files/73707.pdf

Michailides, T. J., and Morgan, D. P. 2004. Panicle and Shoot Blight of Pistachio: A Major Threat to the California Pistachio Industry. APSnet Feature. The American Phytopathological Society, St. Paul, MN.

Nelson, P. E., Toussoun, T. A., and Cook, R. J. 1981. Fusarium: Diseases, Biology, and Taxonomy. Pennsylvania State University Press, University Park, PA.

Nemec, S. 1987. Fusarium solani association with branch and trunk cankers on citrus weakened by cold weather in Florida. Mycopathologia 97:143-150.

Nirenberg, H. I. 1976. Untersuchungen über die morphologische und biologische Differenzierung in der Fusarium-Sektion Liseola. Mitt Biol Bundesanst LandForstw Berlin-Dahlem. 169:1-117.

Nouri, M. T., Lawrence, D. P., Holland, L. A., Doll, D. A., Kallsen, C. E. Culumber, C. M., and Trouillas, F. P. 2019. Identification and pathogenicity of fungal species associated with canker diseases of pistachio in California. Plant Dis. doi:10.1094/PDIS-10-18-1717-RE.

O'Donnell, K., Kistler, H. C., Cigelnik, E., and Ploetz, R. C. 1998. Multiple evolutionary origins of the fungus causing Panama disease of banana: Concordant evidence from nuclear and mitochondrial gene genealogies. Proc. Natl. Acad. Sci. 95:2044-2049.

Pryor, B. M., and Michailides, T. J. 2002. Morphological, pathogenic, and molecular characterization of Alternaria isolates associated with Alternaria late blight of pistachio. Phytopathology 92:406-416.

Rayner, R. W. 1970. A Mycological Colour Chart. Commonwealth Mycological Institute, Kew, United Kingdom.

Reeb, V., Lutzoni, F., and Roux, C. 2004. Contribution of RPB2 to multilocus phylogenetic studies of the euascomycetes (Pezizomycotina, Fungi) with special emphasis on the lichen-forming Acarosporaceae and evolution of polyspory. Mol. Phylogenet. Evol. 32:1036-1060.

Sandoval-Denis, M., Guarnaccia, V., Polizzi, G., and Crous, P. W. 2018. Symptomatic Citrus trees reveal a new pathogenic lineage in Fusarium and two new Neocosmospora species. Persoonia 40:1-25.

Schoeneweiss, D. F. 1981. The role of environmental stress in diseases of woody plants. Plant Dis. 65:308-314.

Skovgaard, K., Nirenberg, H. I., O'Donnell, K., and Rosendahl, S. 2001. Evolution of Fusarium oxysporum f.sp. vasinfectum races inferred from multigene genealogies. Phytopathology 91:1231-1237.

Swofford, D. L. 2002. PAUP*. Phylogenetic Analysis Using Parsimony (*and Other Methods). Version 4.0b10. Sinauer Associates, Sunderland, MA.

Tamura, K., Stecher, G., Peterson, D., Filipski, A., and Kumar, S. 2013. MEGA6: Molecular evolutionary genetics analysis version 6.0. Mol. Biol. Evol. 30: 2725-2729.

Triki, M. A., Rhouma, A., Chaabouni, A. C., and Ioos, R. 2009. Emergence of Fusarium solani causing root rot of pistachio trees in Tunisia. in: Vth International Symposium on Pistachios and Almonds. ISHS Acta Horticulturae 912:717-721, Sanliurfa, Turkey.

Úrbez-Torres, J. R., Boulé, J., Haag, P., Hampson, C. R., and O’Gorman, D. T. 2016. First report of root and crown rot caused by Fusarium oxysporum on sweet cherry (Prunus avium L.) in British Columbia. Plant Dis. 100:855.

Zhang, L. X., Song, J. H., Shen, J. T., Tan, G. J., Li, S. S., and Ding, F. 2013. First report of stem canker on Phoenix tree (Firmiana simplex) caused by Fusarium oxysporum in China. J. Phytopathol. 161:128-130. 